\title{
A case report: acute pancreatitis associated with tacrolimus in kidney transplantation
}

\author{
Junnan $X u^{1,2,3}$, Liang $X u^{1,2,3}$, Xing $W^{i^{1,2}}{ }^{\text {Xiang }} \mathrm{Li}^{1,2}$ and Ming $C \mathrm{ai}^{1,2,3^{*}}$
}

\begin{abstract}
Background: Tacrolimus has been widely used for immunosuppressive therapy in solid organ transplantation (SOT) and allo-geneic stem cell transplantation (allo-SCT) over the past 2 decades. Pancreatitis caused by tacrolimus was rarely reported in kidney transplantation previously.

Case presentation: Here we presented a case of a 45-year-old male who underwent kidney transplantation and received immunosuppressive therapy of tacrolimus, on day +67 after transplantation he developed acute pancreatitis with extremely high blood concentration of tacrolimus. We excluded other possible causes and speculated tacrolimus was the probable inducer of pancreatitis. After tacrolimus was discontinued and alternated with cyclosporine, he gradually recovered and was discharged home with no relapse.
\end{abstract}

Conclusion: Tacrolimus can be a probable cause of pancreatitis after kidney transplantation. We recommended clinicians to be aware of the possibility of tacrolimus-induced pancreatitis during tacrolimus treatment.

Keywords: Acute pancreatitis, Tacrolimus, FK506, Kidney transplantation

\section{Background}

Drug-induced pancreatitis is an adverse effect associated with varies of drugs, more than one hundred drugs have been reported to be the probable causes of pancreatitis $[1,2]$. Pancreatitis, reported in SOT and allo-SCT cases, was considered to be related with immunosuppressive agents. However, only azathioprine has been confirmed to be the cause of pancreatitis with solid evidence so far [3].

Tacrolimus is a commonly used immunosuprressant with variety of adverse effects, including neurotoxicity, hepatotoxicity, nephrotoxicity, infection and so on. However, very few cases that associated pancreatitis with tacrolimus were reported, especially in kidney transplantation [4-7]. Here, we presented an additional case of pancreatitis in a male kidney transplant recipient who received tacrolimus treatment after transplantation.

\footnotetext{
* Correspondence: caiming2002@hotmail.com

'Organ Transplant Institute of People's Liberation Army, the 309th Hospital of People's Liberation Army, Beijing, China

${ }^{2}$ Beijing Key Laboratory of Immunology Regulatory and Organ

Transplantation, Beijing, China

Full list of author information is available at the end of the article
}

\section{Case presentation}

The patient was a 45-year-old male who was admitted to our institution due to uremia. He had no diabetes and biliary tract disease history, and his BMI (body mass index) was $22.99 \mathrm{~kg} / \mathrm{m}^{2}(183 \mathrm{~cm}, 77 \mathrm{~kg})$. He underwent kidney transplantation in our institution on 9th August, 2017. The donor was from donation after cardiac death (DCD). Before surgery, he received antilymphocyte therapy of basiliximab (20 mg i.v.). The surgery was successful and the initial immunosuppressive regimen consisted of tacrolimus ( $6 \mathrm{mg} /$ day, $0.078 \mathrm{mg} / \mathrm{kg} /$ day), mycophenolate mofetil $(1500 \mathrm{mg} /$ day) and corticosteroids (initial dose $35 \mathrm{mg} /$ day). The patient recovered well after surgery and was discharged on day $26+$ with blood creatine level 156.6umol/L and trough concentration of tacrolimus $10.6 \mathrm{ng} / \mathrm{ml}$ then. After discharged, He reexamined in our institution once a week. From day $26+$ to day $60+$, the reexamine results showed his blood creatine level continued to decline to $101.7 \mathrm{umol} / \mathrm{L}$ (day $60+$ ), the dosage of corticosteroids was gradually tapered from 35 $\mathrm{mg} /$ day to $5 \mathrm{mg} /$ day, and the dosage of tacrolimus was maintained at $6 \mathrm{mg} / \mathrm{d}$ with trough concentration ranged from $9.5-11.2 \mathrm{ng} / \mathrm{ml}$. In addition, the recipient neither had a history of high fat diet nor presented hyperlipidemia from day $1+$ to $67+$ posttransplant, the laboratory 
analysis results showed the serum triglyceride (TG) level was in the range of $0.71-1.43 \mathrm{mmol} / \mathrm{L}$ while the cholesterol (CHOL) level was $3.3-4.5 \mathrm{mmol} / \mathrm{L}$ during the period.

On day $67+$, he presented with acute abdominal pain in middle and left area of abdomen accompanied with nausea and vomiting. Physical examination showed diffuse abdominal tenderness with diminish bowel sound. Laboratory analysis showed WBC $9.16 \times 10^{9} / \mathrm{L}$, neutrophils $7.98 \times 10^{9} / \mathrm{L}$, hemoglobin $73 \mathrm{~g} / \mathrm{L}$, platelets $78 \times 10^{9} /$ $\mathrm{L}$, blood creatinine $147.4 \mathrm{umol} / \mathrm{L}$, blood urea nitrogen (BUN) $17.79 \mathrm{mmol} / \mathrm{L}$, calcium $2.52 \mathrm{mmol} / \mathrm{L}$, potassium $4.72 \mathrm{mmol} / \mathrm{L}$, sodium $138 \mathrm{mmol} / \mathrm{L}$, serum amylase 679.3 IU/L (normal 15-115), lipase 755 U/L (normal 6-51), trough concentration tacrolimus $>30 \mathrm{ng} / \mathrm{ml}$ (dosage was $6 \mathrm{mg} /$ day) accompanied with elevated fasting blood glucose $(29.49 \mathrm{mmol} / \mathrm{L})$ and diabetic ketoacidosis (DKA) tendercy (blood ketone body test + ). Abdominal computed tomography scan showed enlarged pancreatic head with peripancreatic inflammation and inflammatory exudate without dilatation of biliary tract (Fig. 1). Pancreatitis diagnosis was made on the basis of the information all above.
Tacrolimus treatment was discontinued, somatostatin (3 mg, q12h, i.v.) was administrated to treat pancreatitis, other treatments included fluid replacement, insulin (i.v.) and imipenem ( $1 \mathrm{~g}, \mathrm{q} 12 \mathrm{~h}$, i.v.). Three days after somatostatin using (day 70+), patient's condition improved significantly, abdomen symptoms relieved, blood amylase level were normalized (72 IU/L) and lipase level deceased to $69 \mathrm{U} / \mathrm{L}$, blood glucose level maintained around $10-15 \mathrm{mmol} / \mathrm{L}$. Cyclosporine $(4 \mathrm{mg} / \mathrm{kg} /$ day $)$ was administrated as an alternative for tacrolimus on day $75+$, and the patient was discharged on day $80+$.

There was no recurrence of pancreatitis in 7 months follow up.

\section{Discussion and conclusions}

Pancreatitis after SOT or allo-SCT have been associated with immunosuppressive treatment previously. However, among the immunosuppressive drugs commonly used, only azathioprine was proved to be the definite cause of pancreatitis [1]. Though tacrolimus has been widely used in transplantation over the past two decades, pancreatitis induced by tacrolimus was rarely reported. In kidney

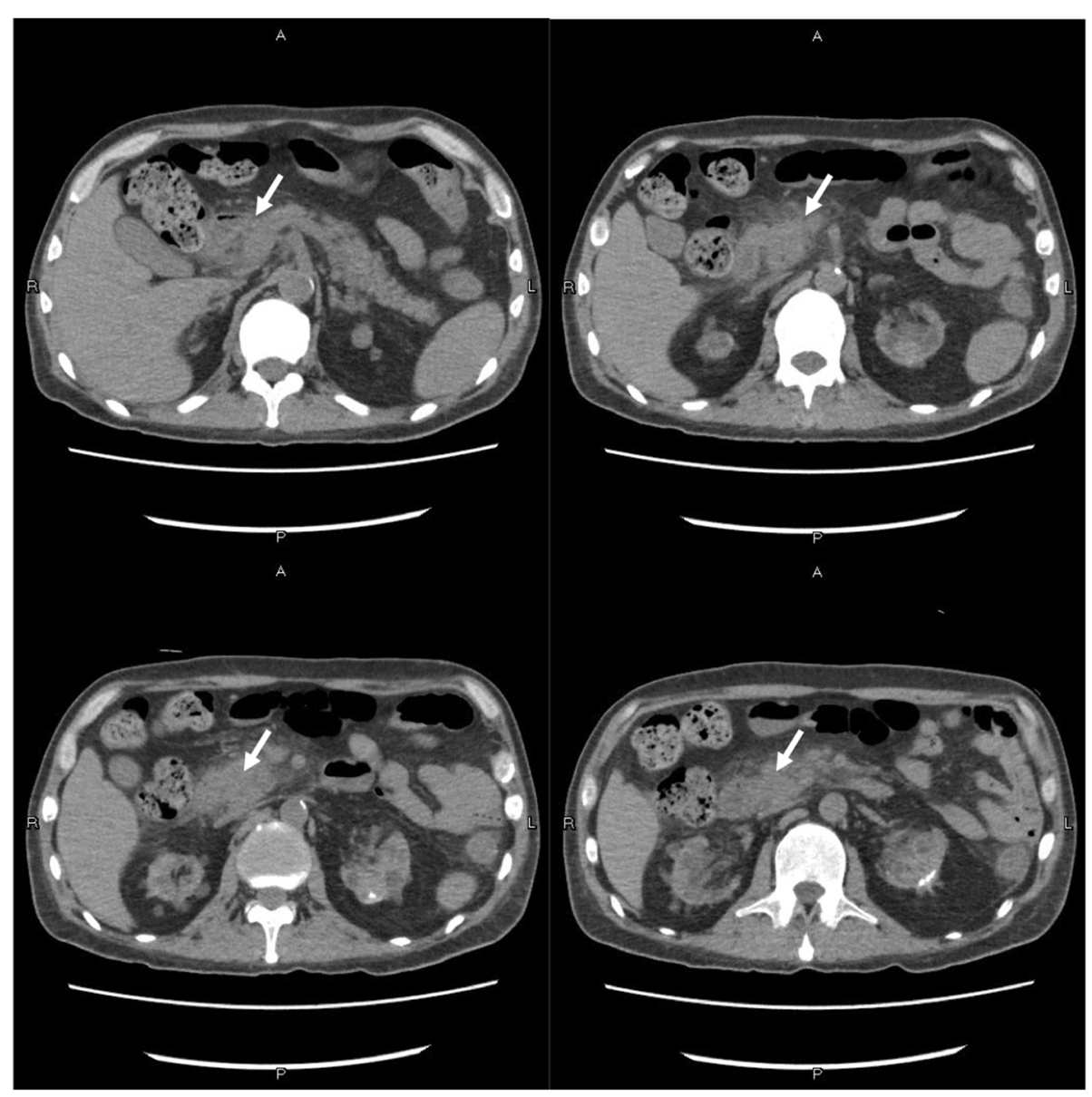

Fig. 1 Abdominal computed tomography scan showed swelling pancreatic head and peripancreatic inflammation (white arrow) 
transplantation, only one case was reported by Ogunsiende et al. suggested tacrolimus was the probable cause of acute pancreatitis [4]. Other cases were from heart, liver and allogeneic umbilical cord blood transplantation [5-7].

In our case, at the time onset of pancreatitis, the patient was receiving varies of drugs including tacrolimus, mycophenolate mofetil, corticosteroids, calcitriol, rabeprazole, nifedipine. Besides tacrolimus, only corticosteroids were reported to be the probable cause of pancreatitis. However, the dosage of corticosteroids was kept at low level (5 $\mathrm{mg} / \mathrm{d}$ ) when acute pancreatitis was presented. Moreover, pancreatitis was relieved and did not relapse with corticosteroids withheld. Therefore, corticosteroids in this case can be reasonably excluded as the cause of pancreatitis.

Other possible causes can also be excluded in this case. Extrahepatic biliary obstruction, hypercalcemia and hyperlipidemia were not observed in CT scan and laboratory examination. No evidence of CMV (cytomegalovirus), zoster, adenovirus or other virus infections was presented. Drugs with definitive association with pancreatitis such as sulfonamides, pentamidine, furosemide was not administrated at the time pancreatitis was presented.

Mallory and Kern established a criterion to identify the association of pancreatitis with any drug. The criteria included:1) appearance of pancreatitis during treatment with the drug; 2) disappearance upon withdrawal of the drug; 3) exclusion of other causes; 4) relapse upon rechallenge [8]. According to Mallory and Kern's criteria, our case meets the first 3 criteria. Since tacrolimus was not readministrated, rechallenge was not available in this patient. Moreover, extremely high trough concentration of tacrolimus coincided with the onset of pancreatitis. Therefore, we consider this case as a probable association between pancreatitis and tacrolimus.

To our knowledge, this is the second report of tacrolimus-induced pancreatitis in kidney transplantation. Although pancreatitis has not been established as an adverse effect of tacrolimus, we would like to alert clinician to the possibility of tacrolimus-induced pancreatitis during tacrolimus treatment.

\footnotetext{
Abbreviations

allo-SCT: Allo-geneic stem cell transplantation; BMI: Body mass index; CMV: Cytomegalovirus; DCD: Donation after cardiac death; DKA: Diabetic ketoacidosis; DKA: Diabetic ketoacidosis; SOT: Solid organ transplantation
}

\section{Acknowledgements}

Not applicable.

\section{Authors' contributions}

MC designed study and critically revised the manuscript. JX examined, the patients, analyzed data and drafted the manuscript. LX and XW contributed to acquisition and interpretation of the clinical data. XL participated in analysis the data and helped to draft the manuscript. All authors read and approved the final manuscript.
Funding

This work was supported by National Natural Science Foundation of China (No. 81770745) and National Natural Science Foundation of China (No. 81800660).

Availability of data and materials

All data supporting our findings are contained within the manuscript.

Ethics approval and consent to participate

Not applicable.

\section{Consent for publication}

Written informed consent was obtained from the patient for publication of this Case Report and any accompanying images. A copy of the written consent is available for review by the Editor of this journal.

\section{Competing interests}

All authors declare that they have no competing interests.

\section{Author details}

${ }^{1}$ Organ Transplant Institute of People's Liberation Army, the 309th Hospital of People's Liberation Army, Beijing, China. ${ }^{2}$ Beijing Key Laboratory of Immunology Regulatory and Organ Transplantation, Beijing, China. ${ }^{3}$ Medical School of Chinese PLA, the Chinese PLA General Hospital, Beijing, China.

Received: 25 May 2018 Accepted: 24 May 2019

Published online: 07 June 2019

\section{References}

1. Tenner S. Drug induced acute pancreatitis: does it exist? World J Gastroenterol. 2014;20(44):16529-34.

2. Tenner S. Drug-induced acute pancreatitis: underdiagnosis and overdiagnosis. Dig Dis Sci. 2010;55(10):2706-8.

3. Floyd A, Pedersen L, Nielsen GL, Thorlacius-Ussing O, Sorensen HT. Risk of acute pancreatitis in users of azathioprine: a population-based case-control study. Am J Gastroenterol. 2003;98(6):1305-8.

4. Ogunseinde BA, Wimmers E, Washington B, lyob M, Cropper T, Callender CO. A case of tacrolimus (FK506)-induced pancreatitis and fatality 2 years postcadaveric renal transplant. Transplantation. 2003;76(2):448.

5. Nieto Y, Russ P, Everson G, Bearman SI, Cagnoni PJ, Jones RB, Shpall EJ. Acute pancreatitis during immunosuppression with tacrolimus following an allogeneic umbilical cord blood transplantation. Bone Marrow Transplant. 2000;26(1):109-11.

6. McDiarmid SV, Klintmalm G, Busuttil RW. FK 506 rescue therapy in liver transplantation: outcome and complications. Transplant Proc. 1991;23(6):2996-9.

7. Im MS, Ahn HS, Cho HJ, Kim KB, Lee HY. Diabetic ketoacidosis associated with acute pancreatitis in a heart transplant recipient treated with tacrolimus. Exp Clin Transplant. 2013;11(1):72-4.

8. Mallory A, Kern F, Jr: Drug-induced pancreatitis: a critical review. Gastroenterology 1980, 78(4):813-820.

\section{Publisher's Note}

Springer Nature remains neutral with regard to jurisdictional claims in published maps and institutional affiliations.
Ready to submit your research? Choose BMC and benefit from:
- fast, convenient online submission
- thorough peer review by experienced researchers in your field
- rapid publication on acceptance
- support for research data, including large and complex data types
- gold Open Access which fosters wider collaboration and increased citations
- maximum visibility for your research: over $100 \mathrm{M}$ website views per year
At BMC, research is always in progress.
Learn more biomedcentral.com/submissions 